\title{
Clinical and microbiological characterization of Staphylococcus lugdunensis isolates obtained from clinical specimens in a hospital in China
}

\author{
Chaojun Liư ${ }^{1}$, Dingxia Shen ${ }^{1 *}$, Jing Guo ${ }^{2}$, Kaifei Wang ${ }^{1}$, Huan Wang ${ }^{1}$, Zhongqiang Yan ${ }^{1}$, Rong Chen ${ }^{1}$ and Liyan Ye
}

\begin{abstract}
Background: Several reports have associated Staphylococcus lugdunensis with the incidence of severe infection in humans; however, the frequency and prevalence of this microorganism and thus the propensity of its antimicrobial drug resistance is unknown in China. The objective of the current study was to determine the prevalence of Staphylococcus lugdunensis among six hundred and seventy non-replicate coagulase negative Staphylococcus (CoNS) isolates collected in a 12-month period from clinical specimens in the General Hospital of the People's Liberation Army in Beijing, China.

Results: Five (0.7\%) of the 670 isolates of CoNS were identified as S. lugdunensis. Whereas three isolates were resistant to erythromycin, clindamycin, and penicillin and carried the ermC gene and a fourth one was resistant to cefoxitin and penicillin and carried the mecA gene, one isolate was not resistant to any of the tested antimicrobials. Pulse field gel electrophoretic analysis did not reveal widespread epidemiological diversity of the different isolates.

Conclusion: Hence, even though S. lugdunensis may be yet unrecognized and undefined in China, it still might be the infrequent cause of infection and profound multi-drug resistance in the same population.
\end{abstract}

Keywords: Staphylococcus lugdunensis, Coagulase-negative staphylococci, Antibiotic resistance, Pulsed-field gel electrophoresis, mecA, ermC

\section{Background}

Staphylococcus lugdunensis is a coagulase-negative staphylococci (CoNS) first described by Freney et al.. in 1988 [1] and usually serves as an aetiologic agent of skin and soft tissue infections, mostly in the pelvic and inguinal regions [2]. In recent years, there have been a number of reports on invasive infections of $S$. lugdunensis resulting in destructive clinical outcome [3-6] and this bacterium has become an increasingly important virulent human pathogen [7]. While S. lugdunensis can cause infections in multiple tissues, including the skin, soft tissue, bone marrow, peritoneum, central nervous system, blood, endocardium, and joints [8], it primarily infects blood, joints, skin, and soft tissue. The blood infection rate of $S$. lugdunensis is around $0.3 \%$ [9], which is lower than most

\footnotetext{
* Correspondence: shendx301@126.com

'Department of Clinical Microbiology, General Hospital of The People's Liberation Army, No. 28 Fu Xing Road, Hai Dian District, Beijing 100853, China

Full list of author information is available at the end of the article
}

other bacteria. However, there are an increasing number of reports on blood infections caused by this bacterium $[10,11]$.

The prevalence of S. lugdunensis varies greatly among different geographical regions, including $1.3 \%$ in Japan [12], $0.8 \%$ in Korea [13], $3 \%$ in the U.S. [14], and $6 \%$ in Argentina [15]. While it is suspected that the incidence of this bacterium in Asiatic countries is similar, its incidence has not yet been investigated in China. One reason for the low detection and underappreciated infection rates of S. lugdunensis are that most clinical microbiology laboratories do not usually speciate CoNS $[7,16]$. Therefore, accurate methods are needed in order to accurately determine incidence by speciation of CoNS isolates. While Frank et al. suggested that ornithine decarboxylase (ODC) and pyrrolidonyl arylamidase (PYR) tests could identify S. lugdunensis from CoNS [17], Tan et al. showed that these two tests could only be used as a preliminarily screen for the bacterium [18]. Currently, it is believed that the sequence of the 
glyceraldehyde-3-phosphate dehydrogenase-encoding (gap) gene can be used to accurately identify S. lugdunensis [19]. Additionally, the current problem of drug resistance in CoNS isolates is severe [20]. The rate of drug resistance of S. lugdunensis varies throughout the world and while it is susceptible to most antibiotics, there are case reports on its resistance to some drugs $[17,18,21,22]$.

The objectives of the present study were to determine the frequency of S. lugdunensis in 670 non-replicate CoNS clinical isolates from the General Hospital of the People's Liberation Army in China and to clinically and microbiologically characterize them. Specifically, we determined drug resistance patterns and molecular epidemiological characteristics, contributing to the clinical diagnosis and treatment of S. lugdunensis infections.

\section{Results}

\section{Detection of S. lugdunensis isolates}

Eight out of the 670 isolates were positive for both ODC and PYR (single positives were not pursued further). Isolate 2 and 4 were positive in the Latex Agglutination test; however, only Isolate 4 was positive in the Slide Coagulase test. All isolates were negative in the subsequent Tube Coagulase test. Of these eight isolates, 4 were further validated by both VITEK 2 GP and API 20 Staph, with a sensitivity of $80 \%(4 / 5)$, one could not be accurately identified by either, and the other 3 were identified as S. haemolyticus (Table 1). The sequences of the gap gene for all 5 isolates were $99 \%$ identical to the corresponding S. lugdunensis sequence (GenBank accession number AF495494.1) (Figure 1). Hence, five out of the 670 CNS isolates were detected as being S. lugdunensis, a detection rate of $0.7 \%$ (5/670). Of the of five S. lugdunensis isolates identified, one was obtained from the venous blood of a patient with influenza, one was from the synovial fluid of a patient with a joint infection, three were from secretions (mammary, cervical, and wound secretions) of patients with skin and soft tissue infections (Table 2).

\section{Characterization of drug resistance in the S. lugdunensis isolates}

Kirby-Bauer (K-B) disc diffusion tests showed that among the five isolates of $S$. lugdunensis, three were resistant to erythromycin (ERM), clindamycin (DA), and penicillin $(\mathrm{P})$, one was resistant to cefoxitin and penicillin and positive for $\beta$-lactamase, and one was susceptible to all antimicrobials and negative for $\beta$-lactamase (Table 3). E-TEST results indicated that the 5 isolates were susceptible to vancomycin (VA) (Table 3). Results for control strains for both methods were within the reference ranges. The $\mathrm{erm} C$ resistance gene was present in 3 of the 5 isolates of S. lugdunensis, as determined by PCR amplification (Figure 2A). None of the isolates had erm $\mathrm{A}$ or erm $\mathrm{B}$ genes (data not shown), whereas the $m e c A$ gene was present in one isolate (Figure $2 \mathrm{~B}$ ). The $\mathrm{PCR}$ results are summarized in Figure $2 \mathrm{C}$.

\section{PFGE did not reveal widespread diversity among the isolates}

After SmaI digestion and electrophoresis, genomic DNA fragments were well separated and 12 to 15 DNA electrophoretic bands were produced (Figure 3). A cluster dendrogram did not reveal widespread diversity, with similarity among the five isolates ranging from $71.7 \%$ to 96.6\%; two pairs of isolates were $96.0 \%$ and $96.6 \%$ similar and one isolate had below $87.3 \%$ similarity to the other isolates (Figure 3).

\section{Discussion}

To the best of our knowledge, this is the first report of prevalence of $S$. lugdunensis in clinical specimens

Table 1 Identification results of API 20 Staph, VITEK 2 GP, gap gene sequencing, tube coagulase, slide coagulase, and latex agglutination tests

\begin{tabular}{|c|c|c|c|c|c|c|}
\hline No. & $\frac{\text { API } 20 \text { Staph }}{\text { (Identification rate }^{1} \text { ) }}$ & $\frac{\text { VITEK } 2 \text { GP }}{\text { (Identification rate }^{1} \text { ) }}$ & $\frac{\text { Gap gene }}{\left(\text { Similarity }^{2}\right)}$ & $\begin{array}{l}\text { Tube } \\
\text { Coagulase }\end{array}$ & $\begin{array}{l}\text { Slide } \\
\text { Coagulase }\end{array}$ & $\begin{array}{l}\text { Latex } \\
\text { Agglutination }\end{array}$ \\
\hline 1 & S. hominis $(73 \%)$ & S. hominis (50\%) & S. lugdunensis (99\%) & -ve & -ve & $-v e$ \\
\hline 2 & S. lugdunensis (90\%) & S. lugdunensis (94\%) & S. lugdunensis (99\%) & -ve & $-v e$ & Positive \\
\hline 3 & S. haemolyticus (96\%) & S. haemolyticus (99\%) & S. haemolyticus (99\%) & -ve & -ve & -ve \\
\hline 4 & S. lugdunensis (85\%) & S. lugdunensis (99\%) & S. lugdunensis (99\%) & -ve & Positive & Positive \\
\hline 5 & S. haemolyticus (53\%) & S. haemolyticus (94\%) & S. haemolyticus (100\%) & -ve & -ve & $-v e$ \\
\hline 6 & S. lugdunensis (94\%) & S. lugdunensis (99\%) & S. lugdunensis (100\%) & -ve & $-v e$ & -ve \\
\hline 7 & S. haemolyticus (92\%) & S. haemolyticus (99\%) & S. haemolyticus (99\%) & -ve & -ve & -ve \\
\hline 8 & S. lugdunensis (94\%) & S. lugdunensis (99\%) & S. lugdunensis (99\%) & -ve & -ve & -ve \\
\hline
\end{tabular}

-ve in Latex Agglutination test signifies no noticeable clearance of the blue background in the latex test; -ve in Slide Coagulase test signifies no visible clumping or clotting using either saline or plasma; -ve in Tube Coagulase test signifies no clot by the end of 4 hours or following 24 hours incubation a room temperature. ${ }^{1}$ The highest percentage of identification.

${ }^{2}$ The highest similarity after aligning by BLAST. 


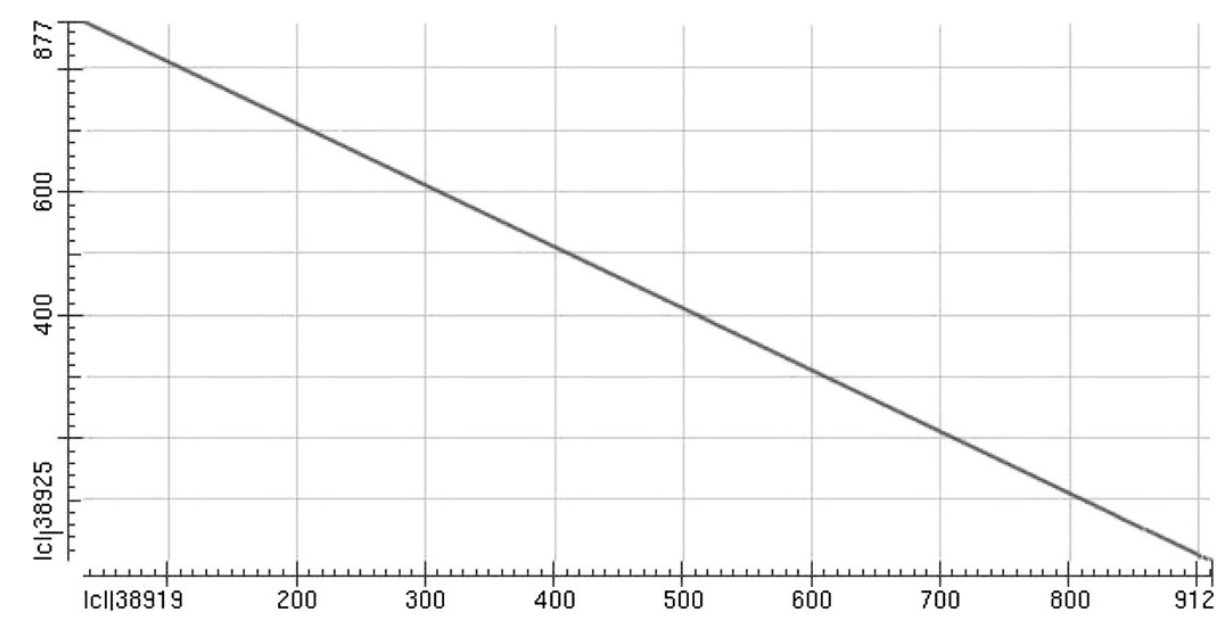

Figure 1 Dot matrix view of the BLAST results showing regions of similarity of the five isolates. The query sequence is represented on the $\mathrm{X}$-axis and the numbers represent the bases/residues of the query. The subjects are represented on the $\mathrm{Y}$-axis and again the numbers represent the bases/residues of the subject. Alignments are shown in the plot as lines. Minus strand matches are slanted from the upper left to the lower right. The number of lines $(n=1)$ shown in the plot is the same as the number of alignments $(n=1)$ found by BLAST. Query coverage was $96 \%$ and maximum identity was $99 \%$.

obtained from mainland China. An earlier case of S. lugdunensis was reported in a 31-year-old Chinese patient (suffering from right ear sinus) in Singapore in 2000 [23]. Recently, community acquired S. lugdunensis were reported in clinical infections associated with comorbidities in Southern Taiwan [24]; however the study did not observe widespread antimicrobial resistance even though there was widespread genetic diversity in the confirmed isolates. In the current study, our detection rate was $0.7 \%(5 / 670)$, which is comparatively on the lower end $[12,14,15]$, but similar to what has been reported in Korea [13].

In the revised manuscript, we have described in details (in the legend of Table 1) what -ve (negative) signifies for the tube coagulase, slide coagulase, and latex agglutination test, respectively.

The latex agglutination test and slide coagulase test are used for rapid identification or for ruling out
Staphylococcus aureus. However, some Staphylococcus isolates produce a membrane-bound form of the clumping factor, which can yield a positive result in slide coagulase and/or rapid latex agglutination tests, thus requiring the confirmatory tube coagulase test. However, an isolate that is positive in the Latex Agglutination test has a high probability of a positive slide coagulase test and our assay for Isolate 2 does not conform to this, whereas Isolate 4 does. In addition, recent results have shown that the prevalence of the fibrinogen-binding adhesion $(f b l)$ is $100 \%$ in Staphylococcus lugdunensis isolates [25]. However, one recent study reported that of the 17 Staphylococcus lugdunensis isolates studied, though $f b l$ gene could be detected in all cases, only $47 \%$ gave a positive slide coagulase test result [26]. This perhaps suggests that varying levels of $f b l$ gene product dictates the apparent sensitivity of Staphylococcus lugdunensis isolates to slide coagulase test. On comparing the

Table 2 Clinical characteristics of S. lugdunensis isolates

\begin{tabular}{|c|c|c|c|c|c|c|c|c|c|}
\hline$\overline{I D}$ & Isolate No. ${ }^{1}$ & Department & $\begin{array}{l}\text { Age (years old)/ } \\
\text { Gender }\end{array}$ & Diagnosis & Fever & $\begin{array}{l}\text { Leukocyte } \\
\text { increase }\end{array}$ & $\begin{array}{l}\text { Specimen } \\
\text { resource }\end{array}$ & $\begin{array}{l}\text { C-reactive } \\
\text { protein (mg/dl) }\end{array}$ & Results \\
\hline 1 & 1010-13169 & $\begin{array}{l}\text { Outpatient } \\
\text { Clinic }\end{array}$ & 48 , female & Mammitis & No & No & Secretion & Unavailable & Heal \\
\hline 2 & 1010-13159 & Orthopedics & 69 , male & $\begin{array}{l}10 \text { years after right knee } \\
\text { joint replacement }\end{array}$ & Yes & No & Synovial fluid & 4.8 & Heal \\
\hline 4 & $1001-17088$ & Obstetrics & 37 , female & $\begin{array}{l}\text { Premature rupture of } \\
\text { fetal membranes, gestational } \\
\text { diabetes }\end{array}$ & Yes & Yes & Cervical secretion & 3.6 & Heal \\
\hline 6 & $1012-23199$ & Orthopedics & 56 , female & $\begin{array}{l}\text { Infection after left tibial } \\
\text { plateau fracture surgery }\end{array}$ & Yes & No & Wound secretion & 7.50 & Heal \\
\hline 8 & $1002-04128$ & Neonate $^{2}$ & 0 , male & $\begin{array}{l}\text { Neonatal pneumonia and } \\
\text { septicemia }\end{array}$ & Yes & No & Venous blood & 0.1 & Heal \\
\hline
\end{tabular}

${ }^{1}$ Isolate No. in the General Hospital of the People's Liberation Army; ${ }^{2}$ The patient was a newborn of 14 days. 
Table 3 Results of drug susceptibility test assayed by the Kirby-Bauer and E-Test and $\beta$-lactamase assay

\begin{tabular}{|c|c|c|c|c|c|c|c|c|c|c|c|c|c|c|c|}
\hline ID & $S A^{1}$ & $\mathrm{CFZ}^{1}$ & $E^{1}$ & FOS $^{1}$ & FOX $^{1}$ & $\mathrm{GM}^{1}$ & $\mathrm{DA}^{1}$ & LVX $^{1}$ & LZD $^{1}$ & $P^{1}$ & $\mathrm{RA}^{1}$ & $\mathrm{CXM}^{1}$ & $\mathrm{SXT}^{1}$ & $V^{2}$ & $\beta$-lactamase \\
\hline 1 & 27 & 34 & $6(\mathrm{R})^{*}$ & 30 & 30 & 26 & $18(\mathrm{R})^{*}$ & 29 & 34 & $15(\mathrm{R})^{*}$ & 32 & 34 & 28 & 1.2 & + \\
\hline 2 & 28 & 34 & $6(\mathrm{R})^{*}$ & 30 & 30 & 28 & $6(R)^{*}$ & 26 & 32 & $14(\mathrm{R})^{*}$ & 34 & 32 & 26 & 1.0 & + \\
\hline 4 & 40 & 44 & 36 & 46 & 28 & 30 & 36 & 28 & 36 & 40 & 40 & 40 & 32 & 1.5 & - \\
\hline 6 & 20 & 38 & $6(\mathrm{R})^{*}$ & 26 & 35 & 26 & $6(\mathrm{R})^{*}$ & 29 & 34 & $9(\mathrm{R})^{*}$ & 38 & 40 & 26 & 1.0 & + \\
\hline 8 & 21 & 24 & 32 & 26 & $18(R)^{*}$ & 27 & 34 & 26 & 34 & $14(\mathrm{R})^{*}$ & 40 & 23 & 32 & 0.8 & + \\
\hline
\end{tabular}

${ }^{1}$ Inhibition zone $(\mathrm{mm}){ }^{2}$ Minimum inhibition concentration (MIC) $(\mu \mathrm{g} / \mathrm{ml})$; ${ }^{*}$ Drug resistant $(R)$.

ID identification directory, SA ampicillin/sulbactam, CFZ cefazolin, ERM erythromycin, FOS fosfomycin, FOX: cefoxitin, GM gentamicin, DA clindamycin

LVX levofloxacin, LZD linezolid, $P$ penicillin, $R A$ rifampicin, CXM cefuroxime, $S X T$ trimethoprim + sulfamethoxazole, $V A$ vancomycin).

results for Isolate 2 and 4 (both positive for latex agglutination test, but only Isolate 4 positive in slide coagulase test), they differ markedly in drug resistance and $\beta$-lactamase expression, with Isolate 4 being susceptible to all drugs tested and the only isolate not expressing $\beta$-lactamase. It is difficult to say whether the $f b l$ gene expression pattern dictates this apparent difference between these isolates; however, it will be very interesting to see in the future if there is any difference in sensitivity to latex agglutination and slide coagulase test based on $f b l$ gene expression in Staphylococcus lugdunensis isolates.

We used PYR and ODC tests to preliminarily screen CNS isolates, VITEK 2 GP and API 20 Staph to validate, and gap gene sequence to confirm S. lugdunensis isolates. There are 27 CoNS species registered in GenBank (Accession numbers DQ321674 to DQ321700). The amplification of the partial gap gene for all of the Staphylococcus species (sequence similarity ranges from 24.3 to $96 \%$ ) yield a single product of nearly $931 \mathrm{bp}$ [19].

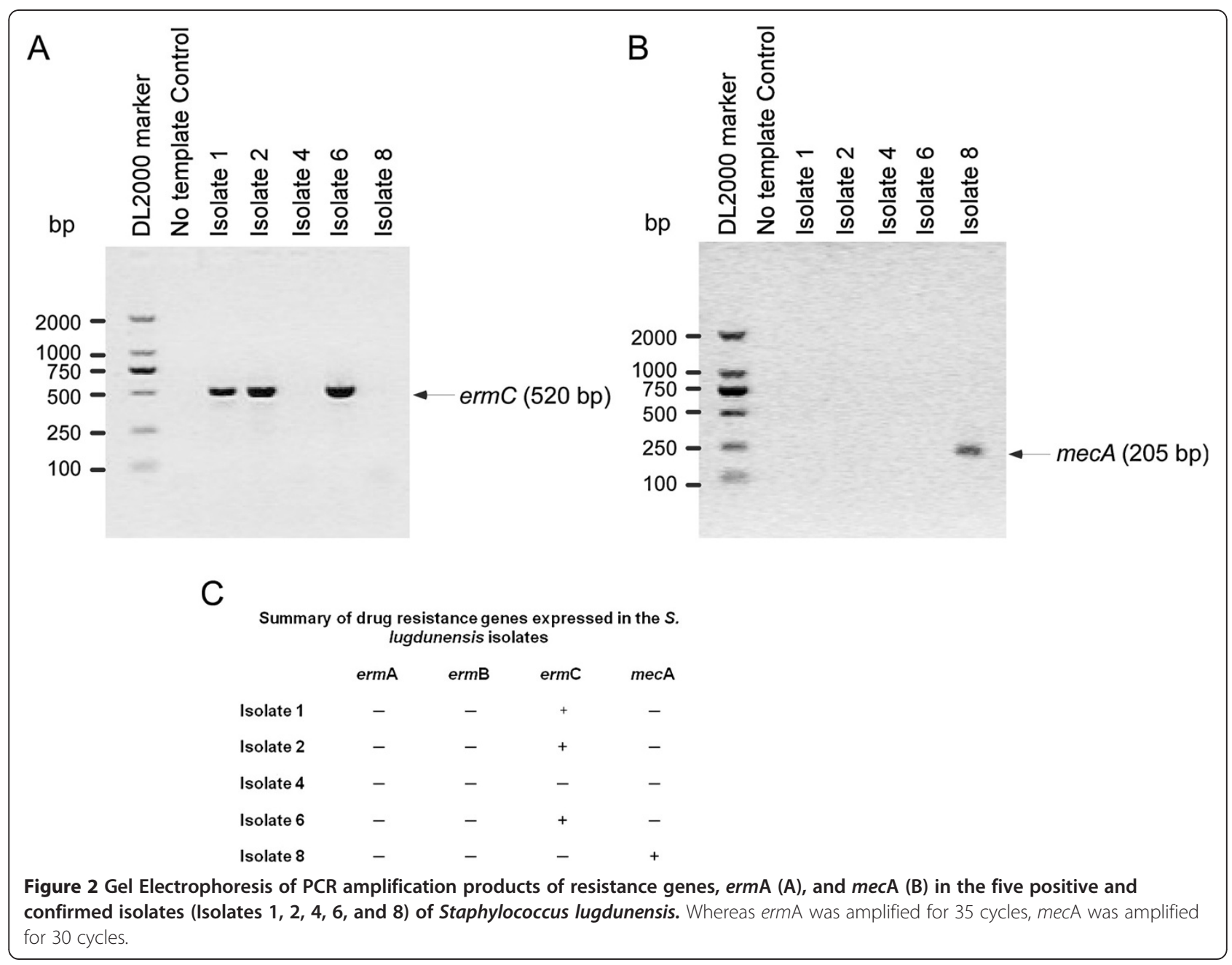




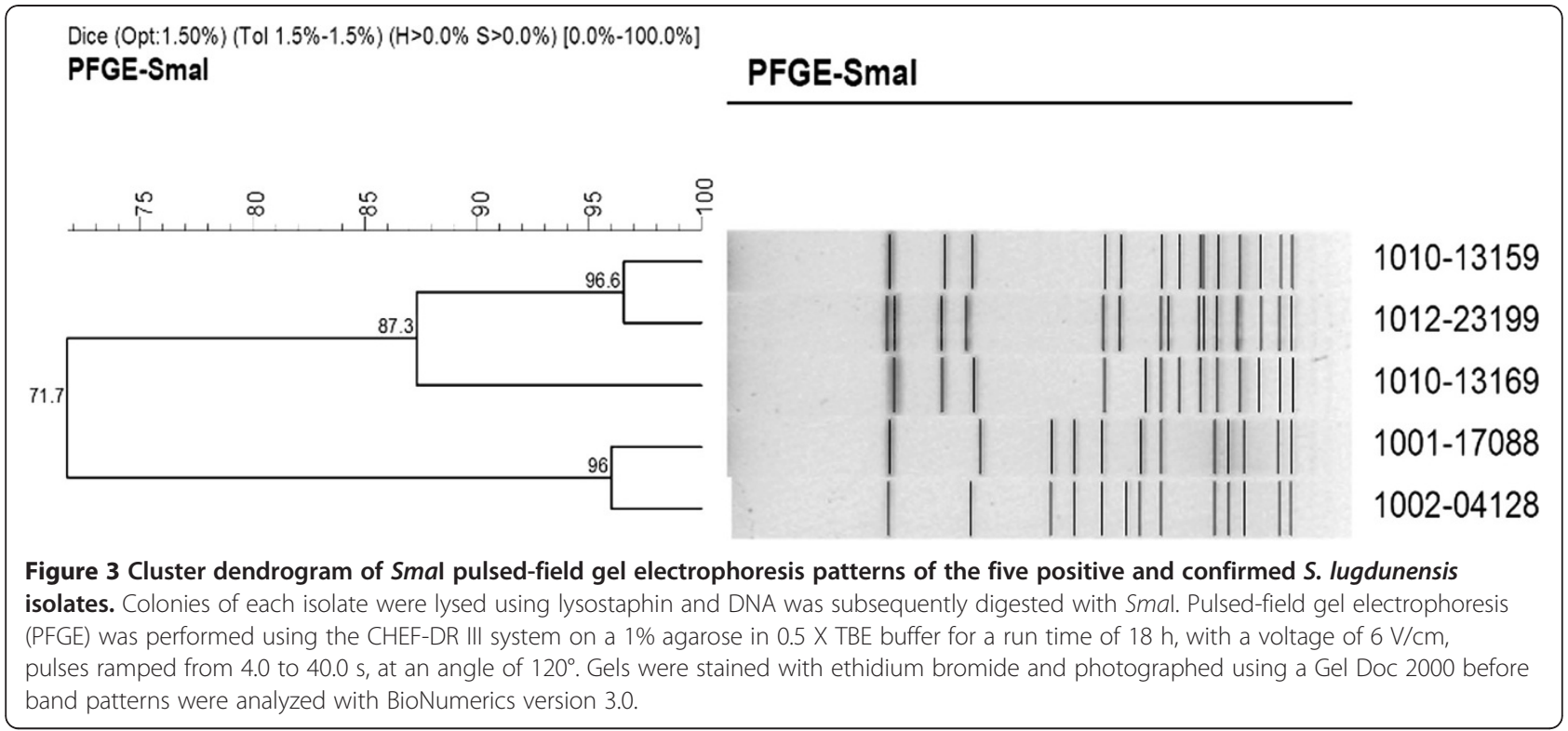

The sequence similarity of the gap sequences ranged from 24.3 to $96 \%$ [19]. In fact, in our analyses the second closest strain was $S$. haemolyticus (data not shown), which has a gap gene sequence similarity of $27 \%$ [19] with S. lugdunensis [19]. We found that among the 8 isolates positive in both PYR and ODC tests, 5 were S. lugdunensis and the other three were S. haemolyticus. This may due to $S$. haemolyticus being weakly positive for ODC, which is consistent with previous results [27].

Of the 5 isolates of $S$. lugdunensis identified in this study, 3 were obtained from wound, breast, and cervix secretions, suggesting that skin and soft tissue infections account for a prominent number of the total infections caused by S. lugdunensis, which is consistent with previous results [17]. One isolate was from the synovial fluid of the patient with a joint infection. Frank et al. reported that this bacterium infects artificially replaced joints [28] and it accounts for $4 \%$ of all joint infections [29]. Another isolate was from the venous blood of a newborn baby with pneumonia. Tee et al. previously reported a case of neonatal pneumonia caused by this bacterium but that case suffered from a catheter-related blood infection [8]. Consistent with previous results [13], S. lugdunensis was not isolated from any sputum cultures in this study, which may be due to inability of this bacterium to colonize the respiratory tract.

Four out of the five $S$. lugdunensis isolates identified in this study produced $\beta$-lactamase (Table 3 ), which indicates an incidence of $80 \%$ that is much higher than the incidence in other countries [17], including $7-24 \%$ in France, $24-40 \%$ in the U.S., $12 \%$ in Spain, and $15 \%$ in Sweden. Of note, our small number of positive isolates might have potentially biased such estimations. Only one out of the five isolates was not resistant to the antimicrobial drugs tested, three were resistant to erythromycin, clindamycin, and penicillin, and one was resistant to cefoxitin and penicillin (Table 3). We found that the three isolates resistant to erythromycin were positive for the erm $C$ gene but not the ermA or ermB gene; and the isolate resistant to cefoxitin was positive for the mecA gene; the later was only reported a few times in the previous studies $[8,30,31]$. We further found that the rate of antibiotic resistance of $S$. lugdunensis is more severe in China than in other countries and primarily presented as multi-drug resistance, again such an inference might suffer from potential bias due to the sample size of the confirmed isolates.

We performed PFGE in order to determine the epidemiological characteristics of $S$. lugdunensis in our hospital, even though the sample size was not ideal for accurately defining epidemiological characteristics. Of note, SmaI-restricted S. lugdunensis in order to gain a band pattern is known to be more difficult compared to $S$. aureus due to methylation of $S m a I$ sites [32]. These isolates were not typed due to the small sample size. However, a cluster dendrogram and clinical analysis still provide epidemiological characteristics. The two isolates with a similarity of $96.0 \%$ were from a patient with a premature rupture of fetal membranes and a 14-day-old newborn. The isolate with a similarity of $87.3 \%$ or less with other isolates was from the outpatient clinic. The two isolates with a similarity of $96.6 \%$ were from the Department of Orthopedics, were both resistant to erythromycin, clindamycin, and penicillin and produce $\beta$-lactamase, suggesting that PFGE can provide epidemiological information for S. lugdunensis from different departments. 


\section{Conclusions}

In summary, while the prevalence of S. lugdunensis in our study is low and warrants further investigations, it is of significant clinical concern that its rate of multi-drug resistance is so high. The diversity of S. lugdunensis by macrorestriction analysis with $S m a \mathrm{I}$ was limited for typing (due to sample size) but sufficient to consider that PFGE with SmaI is suitable for epidemiological analyses. Further studies encompassing detailed molecular methods similar to the current one will be required to characterize the nationwide prevalence and genetic diversity of the $\beta$-lactamase positive $S$. lugdunensis isolated in China.

\section{Methods}

\section{Collection of bacterial isolates}

The Institutional Scientific and Ethics Committees of the General Hospital of the People's Liberation Army approved the current study. Between January and December of 2010, 670 non-replicate isolates of CoNS were collected from clinical specimens in our hospital, inclusive of blood $(\mathrm{n}=74)$, sputa $(\mathrm{n}=188)$, secretions $(\mathrm{n}=84)$, synovial fluid $(\mathrm{n}=17)$, semen $(\mathrm{n}=19)$, drainage fluid $(n=52)$, pus $(n=52)$, nose swabs $(n=20)$, throat swabs $(n=36)$, urine $(n=116)$, catheters $(n=13)$, and others $(\mathrm{n}=36)$. All isolates were obtained after informed consent of the patients. The isolates were all stored at $-86^{\circ} \mathrm{C}$.

\section{DNA extraction}

Bacterial colonies cultured overnight on blood agar plates were suspended in $2 \mathrm{ml} 0.85 \% \mathrm{NaCl}$ solution to 5 McFarland units and centrifuged at 13,000 g for $1 \mathrm{~min}$. The pellets were resuspended in $200 \mu \mathrm{L}$ lysis buffer solution [1\% Triton X-100, $10 \mathrm{mM}$ Tris- $\mathrm{HCl}(\mathrm{pH} \mathrm{8.0)}$, and $1 \mathrm{mM}$ EDTA], boiled for $10 \mathrm{~min}$, and centrifuged at $13,000 \mathrm{~g}$ for $2 \mathrm{~min}$. Supernatants were collected and stored at $-20^{\circ} \mathrm{C}$.

\section{Identification of S. lugdunensis}

S. lugdunensis was isolated and identified from CoNS in three steps. First, the 670 isolates were screened successively with ornithine decarboxylase (ODC) and pyrrolidonyl arylamidase (PYR), and those that were positive for both $(\mathrm{n}=8)$ were considered as suspected isolates of $S$. lugdunensis. Second, the suspected isolates were further validated with API 20 Staph and VITEK 2 grampositive (GP) kits (bioMérieux, France). Finally, the gap gene of the identified $S$. lugdunensis isolates was sequenced as the confirmatory detection tool. The following primers were used to amplify $933 \mathrm{bp}$ of the gap gene [19]: 5'-ATGGTTTTGGTAGAATTGGTC GTTTA-3' (forward) and 5'-GACATTTCGTTATCA TACCAAGCTG-3' (reverse). The PCR reaction was performed in a volume of $25 \mu \mathrm{L}$ with $2.5 \mu \mathrm{L}$ of $10 \times$ PCR Buffer $\left(\mathrm{Mg}^{2+}\right.$ Plus), $2 \mu \mathrm{L}$ of $2.5 \mathrm{mM}$ dNTPs, $1 \mu \mathrm{L}$ of $10 \mu \mathrm{M}$ primers, $0.025 \mathrm{U}$ Taq DNA polymerase (TaKaRa), $15.5 \mu \mathrm{L}$ of double distilled water (DDW), and $4 \mu \mathrm{L}$ of target DNA. The amplification was performed using a Veriti Thermal Cycler (Applied Biosystems, Foster City, CA) with an initial denaturation at $94^{\circ} \mathrm{C}$ for $2 \mathrm{~min}$, 40 cycles of denaturation at $94^{\circ} \mathrm{C}$ for $20 \mathrm{~s}$, annealing at $55^{\circ} \mathrm{C}$ for $30 \mathrm{~s}$, elongation at $72^{\circ} \mathrm{C}$ for $40 \mathrm{~s}$, and a final elongation at $72^{\circ} \mathrm{C}$ for $5 \mathrm{~min}$. The sequences were aligned to the $S$. lugdunensis sequence (GenBank accession number AF495494.1) using the BLASTN 2.2.26+ program [33]. Isolates were confirmed to be S. lugdunensis if the sequence similarity was greater than $99 \%$.

\section{Detection of antimicrobial susceptibility and resistance genes}

$\beta$-lactamase was detected with the rapid detection kit (bioMérieux, France) using Staphylococcus aureus ATCC 29213 as positive control strain and Enterococcus faecalis (ATCC 29212) as a negative control strain. Drug susceptibility tests were performed and interpreted following M100-S20 standards set by the Clinical Laboratory Standards Institute (CLSI) in 2010 [34]. Susceptibility to vancomycin (VA), ampicillin/sulbactam (SA), cefazolin (CFZ), erythromycin (ERM), fosfomycin (FOS), cefoxitin (FOX), gentamicin (GM), clindamycin (DA), levofloxacin (LVX), linezolid (LZD), penicillin (P), rifampicin (RA), cefuroxime (CXM), and trimethoprim + sulfamethoxazole (SXT) was tested with the E-TEST and K-B methods using ATCC29213 and ATCC 25923 as control strains, respectively.

S. lugdunensis isolates were tested for the antibiotic resistance genes ermA, ermB, erm C (erythromycin resistance), and $m e c A$ (cefoxitin resistance) using primer sequence and conditions described before [35-37]. Briefly, the ermA and ermC genes were amplified with an initial denaturation at $95^{\circ} \mathrm{C}$ for $5 \mathrm{~min}$, followed by 35 cycles of denaturation at $95^{\circ} \mathrm{C}$ for $50 \mathrm{~s}$, annealing at $52^{\circ} \mathrm{C}$ for $45 \mathrm{~s}$, elongation at $72^{\circ} \mathrm{C}$ for $50 \mathrm{~s}$, and a final elongation at $72^{\circ} \mathrm{C}$ for $7 \mathrm{~min}$. The parameters for PCR amplification of $\operatorname{ermB}$ were an initial denaturation at $95^{\circ} \mathrm{C}$ for $5 \mathrm{~min}$, then 35 cycles of denaturation at $94^{\circ} \mathrm{C}$ for $50 \mathrm{~s}$, annealing at $55^{\circ} \mathrm{C}$ for $50 \mathrm{~s}$, elongation at $72^{\circ} \mathrm{C}$ for $1 \mathrm{~min}$, and a final elongation at $72^{\circ} \mathrm{C}$ for $7 \mathrm{~min}$. Amplification parameters for the $m e c A$ gene were an initial denaturation at $95^{\circ} \mathrm{C}$ for $5 \mathrm{~min}$, then 30 cycles of denaturation at $95^{\circ} \mathrm{C}$ for $30 \mathrm{~s}$, annealing at $50^{\circ} \mathrm{C}$ for $20 \mathrm{~s}$, elongation at $72^{\circ} \mathrm{C}$ for $20 \mathrm{~s}$, and a final elongation at $72^{\circ} \mathrm{C}$ for $5 \mathrm{~min}$.

\section{Pulsed-Field Gel Electrophoresis (PFGE)}

Colonies of each isolate were suspended in $2 \mathrm{ml}$ cell suspension buffer such that they read 4.5 (colorimeter 
standard, BioMérieux Vitek) on a McFarland Colorimeter. Bacterial cells were lysed using $2 \mu \mathrm{L}$ lysostaphin (1 mg/mL, Sigma) in a $250 \mu \mathrm{L}$ bacterial suspension and DNA was digested with SmaI (TaKaRa). Pulsed-field gel electrophoresis (PFGE) was performed using the CHEFDR III system (Bio-Rad) on a $1 \%$ agarose (Cambraex Bio Science, Rockland) in $0.5 \mathrm{X}$ TBE buffer (45 mM Tris-borate, $1 \mathrm{mM}$ EDTA) for a run time of $18 \mathrm{~h}$, with a voltage of $6 \mathrm{~V} / \mathrm{cm}$, pulses ramped from 4.0 to $40.0 \mathrm{~s}$, at an angle of $120^{\circ}$. The standard strain $\mathrm{H} 9812$ (XbaI enzyme) was used as the electrophoresis marker. Gels were stained with $1 \mu \mathrm{g} / \mathrm{mL}$ ethidium bromide for $30 \mathrm{~min}$, washed in water for $30 \mathrm{~min}$, and photographed using a Gel Doc 2000 (Bio-Rad). Band patterns were analyzed with BioNumerics version 3.0 (Applied Maths BVBA, Belgium) with the Dice coefficient and UPGMA clustering at $1.5 \%$ band tolerance.

\section{Competing interests}

The authors declare that they do not have any competing interest.

\section{Authors' contributions}

C.L. and S.D. designed the experimental plan. C.L. performed most of the experiments; G.J. and W.K. did strain collection and isolation, respectively; W. H. did gap gene sequencing analysis; Y.Z. performed PFGE data analysis; C.R. participated in strain identification Y.L. performed drug resistance phenotype detection; C.L. and S.D. analyzed the data and wrote the manuscript; all authors have reviewed the manuscript.

\section{Acknowledgments}

We thank Research Fellow Wei Li and Associate Research Fellow Jinhua Cui of PulseNET China of Institute for Infectious Disease Control and Prevention (ICDC) of Chinese Center for Disease Control and Prevention (China CDC) for helping in PFGE techniques in the epidemiological study.

\section{Author details}

'Department of Clinical Microbiology, General Hospital of The People's Liberation Army, No. 28 Fu Xing Road, Hai Dian District, Beijing 100853, China. ${ }^{2}$ Clinical Laboratory, The 261st Hospital of The People's Liberation Army, Beijing, China.

Received: 21 February 2012 Accepted: 17 July 2012

Published: 6 August 2012

\section{References}

1. Freney J, Brun Y, Bes M, Meugnier H, Grimont F, Grimont PAD, Nervi C, Fleurette J: Staphylococcus lugdunensis sp. nov. and Staphylococcus schleiferi sp. nov., Two Species from Human Clinical Specimens. Int I Syst Bacteriol 1988, 38:168-172.

2. Bieber L, Kahlmeter G: Staphylococcus lugdunensis in several niches of the normal skin flora. Clin Microbiol Infect 2010, 16:385-388.

3. Anquera I, Del Río A, Miró JM, et al: Staphylococcus lugdunensis infective endocarditis: description of 10 cases and analysis of native valve, prosthetic valve, and pacemaker lead endocarditis clinical profiles. Heart 2005, 91:e10.

4. Grupper M, Potasman I, Rosner I, Slobodin G, Rozenbaum M: Septic arthritis due to Staphylococcus lugdunensis in a native joint. Rheumatol Int 2010, 30:1231-1233

5. Mei-Dan O, Mann G, Steinbacher G, Ballester S, Cugat R, Alvarez P: Septic arthritis with Staphylococcus lugdunensis following arthroscopic ACL revision with BPTB allograft. Knee Surg Sport Traumatol Arthrosc 2008 16:15-18.

6. Pada S, Lye DC, Leo YS, Barkham T: Utility of $16 \mathrm{~S}$ ribosomal DNA sequencing in the diagnosis of Staphylococcus lugdunensis native valve infective endocarditis: case report and literature review. IIID Off Publ Int Soc Infect Dis 2009, 13:e511-e513.
7. Kleiner E, Monk AB, Archer GL, Forbes BA: Clinical significance of Staphylococcus lugdunensis isolated from routine cultures. Clin Infect Dis 2010, 51:801-803.

8. Tee WSN, Soh SY, Lin R, Loo LH: Staphylococcus lugdunensis Carrying the mecA Gene Causes Catheter-Associated Bloodstream Infection in Premature Neonate. J Clin Microbiol 2003, 41:519-520.

9. Pfaller MA, Jones RN, Doern GV, Sader HS, Kugler KC, Beach ML: Survey of blood stream infections attributable to gram-positive cocci: frequency of occurrence and antimicrobial susceptibility of isolates collected in 1997 in the United States, Canada, and Latin America from the SENTRY antimicrobial surveillance program. Diagn Microbiol Infect Dis 1999, 33:283-297.

10. Choi S-H, Chung J-W, Lee E-J, et al: Incidence, characteristics, and outcomes of Staphylococcus lugdunensis bacteremia. J Clin Microbiol 2010, 48:3346-3349

11. Fadel HJ, Patel R, Vetter EA, Baddour LM: Clinical Significance of a Single Staphylococcus lugdunensis-Positive Blood Culture. J Clin Microbiol 2011, 49:1697-1699.

12. Kawamura Y, Hou X-G, Sultana F, et al: Distribution of Staphylococcus species among human clinical specimens and emended description of Staphylococcus caprae. J Clin Microbiol 1998, 36:2038-2042

13. Shin JH, Jung HJ, Lee HR, Kim JH, Kim HR, Lee JN: Prevalence, identification, and antimicrobial susceptibility of Staphylococcus lugdunensis from various clinical specimens in Korea. Jpn J Infect Dis 2007, 60:312.

14. Kleeman KT, Bannerman TL, Kloos WE: Species distribution of coagulasenegative staphylococcal isolates at a community hospital and implications for selection of staphylococcal identification procedures. Clin Microbiol 1993, 31:1318-1321.

15. De Paulis AN, Predari SC, Chazarreta CD, Santoianni JE: Five-test simple scheme for species-level identification of clinically significant coagulase-negative Staphylococci. J Clin Microbiol 2003, 41:1219-1224.

16. Gatermann SG, Koschinski T, Friedrich S: Distribution and expression of macrolide resistance genes in coagulase-negative staphylococci. Clin Microbiol Infect 2007, 13:777-781.

17. Frank KL, del Pozo JL, Patel R: From clinical microbiology to infection pathogenesis: How daring to be different works for Staphylococcus lugdunensis. Clin Microbiol Rev 2008, 21:111-133.

18. Tan TY, Ng SY, He J: Microbiological characteristics, presumptive identification, and antibiotic susceptibilities of Staphylococcus lugdunensis. J Clin Microbiol 2008, 46:2393-2395.

19. Ghebremedhin B, Layer F, König W, König B: Genetic classification and distinguishing of Staphylococcus species based on different partial gap, $16 \mathrm{~S}$ rRNA, hsp60, rpoB, sodA, and tuf gene sequences. J Clin Microbiol 2008, 46:1019-1025.

20. Piette $A$, Verschraegen $G$ : Role of coagulase-negative staphylococci in human disease. Vet Microbiol 2009, 134:45-54.

21. Hellbacher C, Törnqvist E, Söderquist B: Staphylococcus lugdunensis: clinical spectrum, antibiotic susceptibility, and phenotypic and genotypic patterns of 39 isolates. Clin Microbiol Infec 2006, 12:43-49.

22. van der Mee-Marquet N, Achard A, Mereghetti L, Danton A, Minier M, Quentin R: Staphylococcus lugdunensis infections: high frequency of inguinal area carriage. J Clin Microbiol 2003, 41:1404-1409.

23. Ling ML, Yeo M: Staphylococcus lugdunensis: Report of first case of skin and soft issue infection in Singapore. Singapore Med J 2000, 41:177-178.

24. Wu A-B, Wang M-C, Tseng C-C, et al: Clinical and microbiological characteristics of community-acquired Staphylococcus lugdunensis infections in Southern Taiwan. J Clin Microbiol 2011, 49:3015-3018.

25. Pereira EM, Teixeria CA, Alvarenga AL, et al: A Brazilian lineage of Staphylococcus lugdunensis presenting rough colony morphology may adhere to and invade lung epithelial cells. J Med Microbiol 2012, 61:463-469

26. Chatzigeorgious KS, Siafakas N, Peinaki E, Zerva L: fbl gene as a speciesspecific target for Staphylococcus lugdunensis identification. J Clin Lab Anal 2010, 24:119-122.

27. Schnitzler N, Meilicke R, Conrads G, Frank D, Haase G: Staphylococcus lugdunensis: Report of a case of peritonitis and an easy-to-perform screening strategy. J Clin Microbiol 1998, 36:812-813.

28. Frank KL, Hanssen AD, Patel R: icaA is not a useful diagnostic marker for prosthetic joint infection. J Clin Microbiol 2004, 42:4846-4849. 
29. Trampuz A, Piper KE, Jacobson MJ, et al: Sonication of removed hip and knee prostheses for diagnosis of infection. N Engl J Med 2007, 357:654-663.

30. Becker K, Pagnier I, Schuhen B, et al: Does nasal cocolonization by methicillin-resistant coagulase-negative staphylococci and methicillinsusceptible Staphylococcus aureus strains occur frequently enough to represent a risk of false-positive methicillin-resistant $\mathrm{S}$. aureus determinations by molecular methods? J Clin Microbiol 2006, 44:229-231.

31. Pereira EM, Schuenck RP, Nouer SA, et al: Methicillin-resistant Staphylococcus lugdunensis carrying SCCmec type V misidentified as MRSA. Braz J Infect Dis 2011, 15:293-295.

32. van der Mee-Marquet N, Achard A, Mereghetti L, et al: Staphylococcus lugdunensis infections: high frequency of inguinal area cartilage. J Clin Microbiol 2003, 41:1404-1409.

33. Zhang Z, Schwartz S, Wagner L, Miller W: A greedy algorithm for aligning DNA sequences. J Comput Biol 2000, 7:203-214.

34. Clinical and Laboratory Standards Institute: Performance standards for antimicrobial susceptibility testing: 19th informational supplement. CLSI document M100-S21. Wayne, PA: Clinical and Laboratory Standards Institute; 2011.

35. Lina G, Quaglia A, Reverdy ME, Leclercq R, Vandenesch F, Etienne J: Distribution of genes encoding resistance to macrolides, lincosamides, and streptogramins among staphylococci. Antimicrob Agents Chemother 1999, 43:1062-1066

36. Khan SA, Nawaz MS, Khan AA, Cerniglia CE: Simultaneous detection of erythromycin-resistant methylase genes ermA and ermC from Staphylococcus spp. by multiplex-PCR. Mol Cell Probes 1999, 13:381-387.

37. Rohrer S, Tschierske M, Zbinden R, Berger-Bächi B: Improved methods for detection of methicillin-resistant Staphylococcus aureus. Eur J Clin Microbiol 2001, 20:267-270.

doi:10.1186/1471-2180-12-168

Cite this article as: Liu et al.: Clinical and microbiological

characterization of Staphylococcus lugdunensis isolates obtained from clinical specimens in a hospital in China. BMC Microbiology 2012 12:168

\section{Submit your next manuscript to BioMed Central and take full advantage of:}

- Convenient online submission

- Thorough peer review

- No space constraints or color figure charges

- Immediate publication on acceptance

- Inclusion in PubMed, CAS, Scopus and Google Scholar

- Research which is freely available for redistribution 